явно нелинеарная, что обусловлено, с одной стороны, «собственной» кривизной роста ребрышек (особенно в задне-боковых частях створки) и, с другой стороны, степенью выпуклости створки. Другими словами, последний графический способ сравнения дает безоговорочно однозначные результаты только для створок, выпуклости которых сопоставимы.

Отметим еще, что расстояние от макушки до места появления однотипных отщепляющихся ребрышек в пределах одного вида относительно ностоянное (рис. 3 Г) и имеет, по-видимому, диагностическое значение (ср. рис. 2 ІБ, ІІБ, ІВ и ІІВ).

\title{
ЛИТЕРАТУРА
}

B a n croft B. B. 1928a. On the notational representatien of the rib-system in Orthacea. Manchester Memories, 72, No. 7.

B a n c r of t B. B. 1928b. The Harknessellinae. Manchester Memories, 72, No. 12.

B a n croft B. B. 1945. The Brachiopod zonal indices of the stages Costonian to Onnian in Britain. J. Paleont., 19, No. 2.

Kemezy s K. J. 1968. Arrangements of costellae, setae and vascula in Enteletacean brachiopods. J. Paleont., 42, No. 1.

Temple J. T. 1965. Upper Ordovician brachiopods from Poland and Britain. Acta Paleont. Pol., 10, No. 3.

Williams A. 1963. The Caradocian brachiopod faunas of the Bala District, Merionethshire. Bull. Brit. Mus. (Nat. Hist.), Geol., 8, No. 7.

Williams A. and Wright A. D. 1963. The classification of the "Orthis testudinaria Dalman" group of. brachiopods. J. Paleont., 37, No. 1.

Wright A. D. 1964. The fauna of Portrane Limestone. Bull. Brit. Mus (Nat. Hist.), Geol,, 9, No. 6.
Институт геологии
Академии наук Эстонской СCP
Постулнла в редакцню 18/X 1968

\author{
EESTI NSV TEADUSTE AKADEEMIA TOIMETISED. XVIII KOIDE \\ KEEMIA * GEOLOOGIA. 1969, Nr. 1 \\ ИЗВЕСТИЯ АКАДЕМИИ НАУК ЭСТОНСКОИ ССР. ТОМ ХVIII \\ Химия - ГЕолоГия. 1969, * 1
}

O. KIRRET, I. ARRO, H. HEINLO

\section{CHROMOSORB W KASUTAMISEST ELEKTROFOREESIL ANTIKONVEKTSE MATERJALINA}

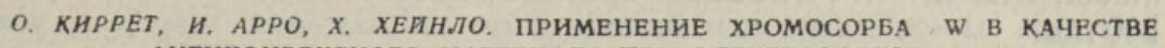
АНТИКОНВЕКТНОГО МАТЕРИАЛА ПРИ ЭЛЕКТРОФОРЕЗЕ

O. KIRRET, I. ARRO, H. HEINLO. USE OF CHROMOSORB W AS ANTI-CONVECTANT MEDIA IN ELECTROPHORESIS

Elektroforeesil kasutatakse kandva keskkonnana väga mitmesuguseid materjale, nagu filterpaberit, klaashelmeid, anioonseid ja katioonseid vaikusid, polüstüroolhelmeid, peenestatud polüvinüülkloriidi, agargeeli [ $\left.{ }^{1}\right]$, vahtkummi $\left[{ }^{2}\right]$, polüuretaanvahtu $\left[{ }^{3 ; 4}\right]$, poorset klaasi $\left[{ }^{5}\right]$, diatomiiti $\left[{ }^{6}\right]$, silikageeli $\left[{ }^{6}\right]$, etüleeritud tselluloosi $\left[{ }^{7}\right]$ jt.

Okski teada olev materjal aga ei vasta mitte kôikides punktides tänapäeval antikonvektsetele materjalidele esitatavatele nõuetele $\left[{ }^{7,8}\right]$. Sellest tin- 


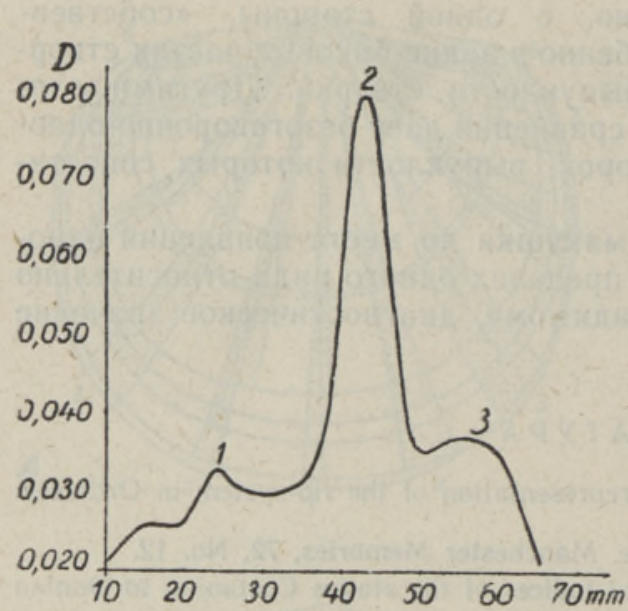

Joonis 1. Trüpsiini elektroforees Chromosorbil W.

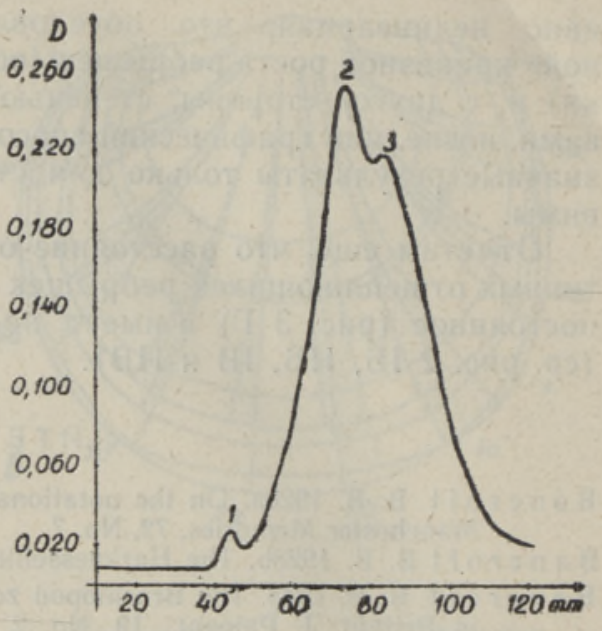

Joonis 2. Trüpsiini elektroforees Whatman nr. 1 paberil.

gitult tuleb kandja valikul alati lähtuda konkreetsetest katsetingimustest ning vastavalt sellele kasutada varianti, kus esinevad puudused minimaalselt häirivad eksperimendi käiku.

Autoreil tuli trüpsiin eraldada lisandeist ja autolüüsi produktidest. Valdav osa selle probleemiga tegelnud uurijaist on elektroforeetilisel lahutamisel kandva keskkonnana kasutanud kas paberit või tärklist $\left[{ }^{9-15}\right]$. Viimaste peamiseks puuduseks on aga see, et happeliste puhvrite kasutamiscl eraldub neist lahustunud komponente, milledel lainepikkusel $280 \mathrm{~m} \mu$ esineb absorptsioon ja mis seega raskendavad eraldunud fraktsioonide edasist spektraalanalüütilist määramist.

Mitmesuguseid aineid uurides selgus, et trüpsiini elektroforeesil on väga heaks antikonvektseks materjaliks Johns Manville'i toodetud Chromosorb W (80/100 mešši). Tema lahutusvõime selgitamiseks suspendeeriti $10 \mathrm{~g}$ Chromosorbi W $50 \mathrm{ml} 0,1 \mathrm{~m}$ formiaatpuhvris, mille $\mathrm{pH}=3,2$. Suspensioonist valati klaasplaadile $7 \times 40 \times 180 \mathrm{~mm}$ suurune plokk. Viimane jäeti 24 tunniks elektroforeesikambrisse, kus ta stabiliseerus ja kus üleliigne puhver valgus kontaktanumasse. Seejärele kanti ploki keskele kuni $7 \mathrm{mg}$ trüpsiini (firma SPOFA, partii 050655). Elektroforees toimus 20 tundi $180 \mathrm{~V}$ pinge juures. Peale elektroforeesi tükeldati plokk $0,5 \mathrm{~cm}$ laiusteks ribadeks, mis ekstraheeriti katseklaasides $4 \mathrm{ml}$ puhvriga ja filtreeriti läbi klaasfiltrite nr. 4. Filtraatide optilised tihedused määrati lainepikkusel $280 \mathrm{~m} \mu$.

Jooniselt 1 selgub, et põhiliselt eraldusid kolm fraktsiooni. Proteolüütiline aktiivsus $\left[{ }^{16}\right]$ esines ainult fraktsioonidel 2 ja 3 , kusjuures viimase aktiivsus oli väga väike ja võis olla tingitud fraktsooni 2 «lõikumisest».

Võrdluseks elektroforeesiti trüpsiini analoogilistel tingimustel ka Whatman nr. 1 paberil. Eraldunud fraktsioonide määramiseks värviti paber broomfenoolsinisega ja lõigati $0,5 \mathrm{~cm}$ laiusteks ribadeks, mis ekstraheeriti $5 \mathrm{ml} 0,01 \mathrm{n} \mathrm{NaOH}$ vesilahusega. Ekstraktide optilised tihedused määrati fotokolorimeetriliselt.

Jooniselt 2 selgub, et ka paberelektroforeesil eraldus kolm fraktsiooni, millede eraldusteravus aga oli väiksem kui Chromosorb W. puhul. 
Katsetest järeldub, et hapetega küllaldaselt töödeldud Chromosorb W on elektroforeesil heade omadustega kandvaks keskkonnaks, kust fraktsioonidesse ei eraldu spektraalanalüüsi segavaid komponente, lahutusteravus aga ületab paberelektroforeesi tulemused.

\title{
K I R J A D US
}

1. Glick D., Methods of Biochemical Analysis I, Interscience Publ. INC, New York, 1954 , pp. $154-155$.

2. Mitchell H. K., Herzenberg L. A., Anal. Chem., 29, 1229 (1957).

3. D a vid s o n H. M., Biochim. biophys. Acta, 34, 67 (1959).

4. Wills E. D., Biochem. J., 69, 178 (1958).

5. M a c D o n e 11 H. L., Anal. Chem., 33, 1554 (1961).

6. P a stuska G., T'rinks H., Chemiker Ztg., 85, 535 (1961); 86, 135 (1962).

7. Morris C. J. O. R., Morris P., Separation Methods in Biochemistry. London, Pitman and Sons LTD, 1963, pp. 664-761.

8. Flodin P., Ku p k e D. W., Biochim. biophys. Acta, 21, 368 (1956).

9. W all enfels K., Pechman E., Angew. Chem., 63, Nr. 2, 44 (1951).

10. Nikkilä E., Ekholm K., S ivol a H., Acta Chem. Scand., 6, No. 5, 617 (1952).

11. Li e ner I. E., V is W a n a th a T., Biochem. biophys. Acta, 22, 299 (1956).

12. Grassmann W., Hannig K., S et leyer M., Z. physiol. Chem., 316, 71 (1959)

13. Perrone J. C., Disitzer L. V., Domont G., Nature, 183, 605 (1959).

14. Perrone J. C., Disitzer L. V., I a chan A., Nature, 184, 1225 (1959).

15. I achan A., Domont G. B., Disitzer L. V., Perrone J. C., Nature, 203, 43 (1964).

16. Lebez D., Bull sci. Conseil. RPF Yougoslaw., 1, No. 2, 44 (1953).

Eesti NSV Teaduste Akadeemia Keemia Instituut

Saabus toimetusse

8. X 1968
EESTI NSV TEADUSTE AKADEEMIA TOIMETISED. XVIII KOIDE
KEEMIA - GEOLOOGIA. 1969, Nr. 1
ИЗВЕСТИЯ АКАДЕМИИ НАУК ЭСТОНСКОИ ССР. ТОМ ХVIII
ХИМИЯ - ГЕОЛОГИЯ. 1969, М 1

\section{ВЛИЯНИЕ ТЕМПЕРАТУРЫ НА ХЕМОСОРБЦИЮ КИСЛОРОДА ПЛАТИНОЙ, НАНЕСЕННОИ НА СИЛИКАГЕЛЬ}

\author{
O. EISEN, A. IVANOV. TEMPERATUURI MOJU HAPNIKU HEMOSORBTSIOONILE PLAATINA- \\ SILIKAGEELKATALOSAATORIL \\ o. EISEN, A. IVANOV. DER EINFLUB DER TEMPERATUR AUF DIE SAUERSTOFFCHEMO- \\ SORPTION AN EINEM PLATIN-KIESELGELKATALYSATOR
}

В связи с широким распространением методов регенерирования платиновых катализаторов воздухом вопрос о взаимодействии платины с кислородом имеет большое практическое значение. Обычно платина считается неокисляющимся металлом. Действительно, из всех металлов платиновой группы платина обладает наименьшим сродством к кислороду, хотя в определенньх условиях $\left(450^{\circ} \mathrm{C}\right)$ к окисляется, образуя закись PtO. Піо данным [ $\left.{ }^{1}\right]$, растворимость кислорода в платине изучена недостаточно, но известно, Фто при $450^{\circ}$ один объем ллатины способен поглотнть до 77 объемов кислорода. 